\title{
A Developmental Research on National Sports Resources in West China Based on PSR Model
}

\author{
Jun Liu, Caixia Wang \\ School of Sports Science, Nantong University, Nantong, China \\ Email:1j697520@ntu.edu.cn
}

How to cite this paper: Liu, J., \& Wang, C. X. (2016). A Developmental Research on National Sports Resources in West China Based on PSR Model. Advances in Physical Education, 6, 292-299.

http://dx.doi.org/10.4236/ape.2016.64030

Received: June 30, 2016

Accepted: September 23, 2016

Published: September 26, 2016

Copyright $\odot 2016$ by authors and Scientific Research Publishing Inc. This work is licensed under the Creative Commons Attribution International License (CC BY 4.0).

http://creativecommons.org/licenses/by/4.0/

\begin{abstract}
West China is rich in unique national sports resources that have not been fully developed and used at present yet. To develop those resources is an important part of the large-scale development strategy for the western region. In this essay, a research on those resources was made based on PSR (Pressure-State-Response) model which is an evaluation model frequently adopted in evaluation of ecosystems health in environmental quality assessment, to analyze the development situation of national sports resources in West China and come up with a theory for relevant development.
\end{abstract}

\section{Keywords}

PSR (Pressure-State-Response), National Sports Resources, Development, Countermeasure

\section{Introduction}

West China is an area retaining multi-national cultures where there are abundant national sports resources including various national sports travelling resources and national sports cultural resources, such as Yak-racing, Wrestling and Tibetan Chess of Tibetan nationality, Torch Festival and Moqiu (a rotating wooden pile game) of Yi nationality, Crossbow Shooting and Liusuo (crossing river by an overhead cable) of Dulong nationality in Yunan, Dragon-boat Racing and Swing of Bai nationality in Yunan, Moqiu and Whipping Top of Hani nationality etc. Relevant data show that there're more than 300 traditional sports events only in Xinjiang area. The spirit of developing the national sports resources in West China is to value these colorful and unique national sports events and pertinent cultures (Nong, 1999). As the advancing of the large-scale development strategy, more or less developed naitonal sports resources in West China have also contributed to the rapid growth of economy in western area. 
However, some problems like relatively delayed continuity of traditional national sports cultures, rather slow development of traditional national sports market, absence of strong support and comprehensive development of national sports resources, arose. The author tried, using PSR model, to analyze the situation of developing and taking advantage of national sports resources in West China, then proposed some theoretical countermeasures aiming at those problems, as reference for a better solution.

\section{Connotation of PSR Model}

PSR (Pressure-State-Response) model was first suggested by Anthony Friend, a Canadian Statistics expert, in 1979 and later adopted by OECD (Organization for Economic Cooperation and Development), then further studied and developed by OECD and UNEP (United Nations Environment Programme) jointly as a framework for studying environmental issues (OECD, 2004). OECD advanced a national-level index system for important global environmental matters covering 13 aspects such as climate changes, ozone layer depletion, eutrophication, acidification, toxic pollution, city environment quality and other problems that are hard to categorize (Cheng, 1987). There's specific "pressure, state and response" index for each aspect. PSR is an evaluation model frequently adopted in evaluation of ecosystems health in environmental quality assessment. This model theory is widely used for effectively analyzing reasons, effects and results (Zhang et al., 2002). The OECD's construction of PSR index framework is consist of pressure (by human activity exerted on environment), state (quality of environment and quantity of natural resources) and social response (the society responses to those changes through environmental policies, common economic policies, department policies and changes of mind and behaviour, as shown in Figure 1 (Qiu \& Song, 2002). PSR (Pressure-State-Response) framework shows clearly the relationship among the influence of huamn activities, feedback state of environment and implementation of policies and measures. It, as a circular evaluation system, also shows fully the influence of human activities on nature and countermeasures made after receiving feedback from environment and nature. To analyze the development situation of the national sports

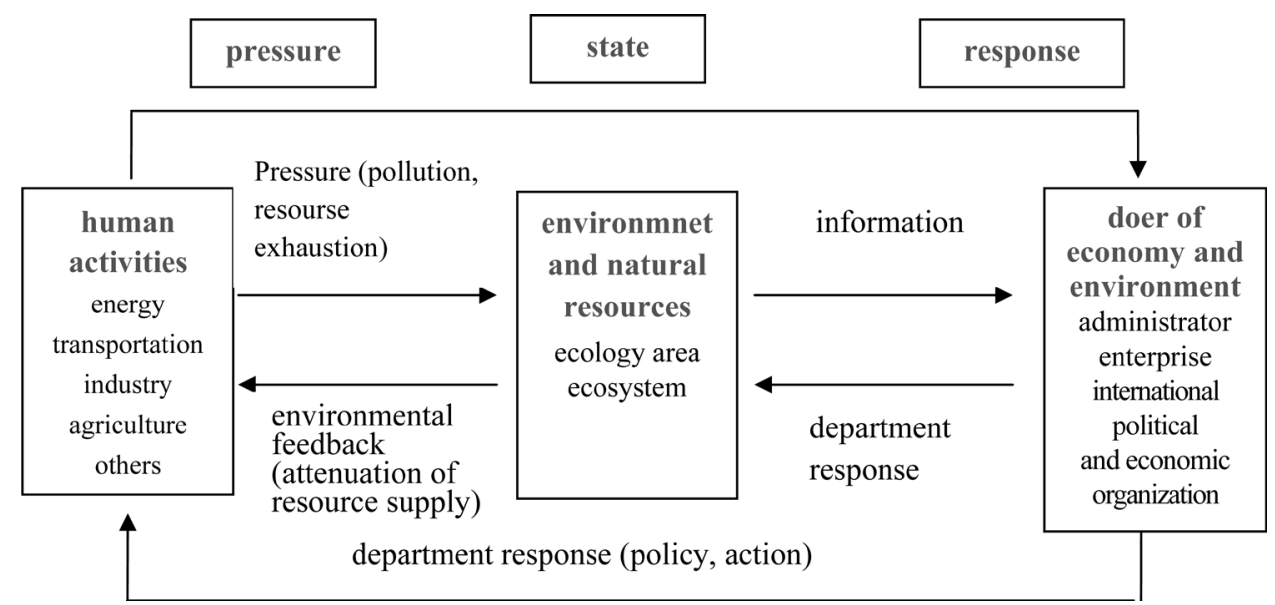

Figure 1. "Pressure-State-Response" model. 
resources in West China by PSR model will reveal problems arose when using and developing those resources and help to find a way to solve the problems, and thereby, promote the development of national sports resources in West China and other resources as well, and accelerate the coordinated and sustainable development around the western area.

\section{Establishing System of the Influence Factors of National Sports Resources Development in West China}

Various influence factors which hinder favorable and sustainable development of sports resources, exist in the development process. Focusing upon an analysis of the influence factors system may make for discovering problems in the national sports resources development and for seeking out solutions. In the PRS framework, "pressure" is the critical link of the entire model and it is the influence factor of sports resources development. With detailed analysis of influence factors system (shown in Figure 2) which includes traditional national culture, national sports market, state government and other factors, problems will be easily find out.

\section{Problems in the Development of Sports Resources in West China in PSR Model}

In PSR model, "pressure" in the development of sports resources in West China refers to human's using those sports resources in all kinds of methods and meanwhile, influencing them in educational, scientific, cultural and policy way. When the sports resources are not reasonably developed and used that they fail to promote harmonious and healthy development of regional economy, the resource developer may get feedback from "state" and then make certain decision and action, that is, "response" to "state". Sustainable development of national sports resources in West China is in need

\begin{tabular}{|c|c|c|}
\hline & types of facto & factors \\
\hline \multirow{4}{*}{ 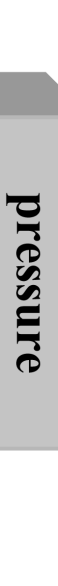 } & $\begin{array}{l}\text { traditional national } \\
\text { events } \\
\text { sports culture }\end{array}$ & $\begin{array}{l}\text { unique and distinctive development of traditional national } \\
\text { events carrying forward and disseminating traditional national } \\
\text { sports culture }\end{array}$ \\
\hline & $\begin{array}{l}\text { national sports } \\
\text { market } \\
\text { producer } \\
\text { operator } \\
\text { consumer }\end{array}$ & $\begin{array}{l}\text { development of global and domestic sports market } \\
\text { scale, pattern and efficiency of producer } \\
\text { model, idea and experience of operator } \\
\text { consuming level and structure of consumer }\end{array}$ \\
\hline & $\begin{array}{l}\text { state government } \\
\text { legistration } \\
\text { policy }\end{array}$ & $\begin{array}{l}\text { supporting situation of state government } \\
\text { making law and legistration } \\
\text { publishing advantagous policies and developing projects }\end{array}$ \\
\hline & $\begin{array}{l}\text { kinds and degree of } \\
\text { resources to } \\
\text { develop }\end{array}$ & $\begin{array}{l}\text { range and quality of sports resources } \\
\text { use and combination of other resources }\end{array}$ \\
\hline
\end{tabular}

Figure 2. System of the influence factors of national sports resources development in west China. 
of coordination of many factors like human, environment and economic benefit. Only through forming human activities, environment and natural resources, economy and environment doer as a favorably circular whole can regional economy enjoy a healthy growth.

\subsection{Relatively Delayed Continuity and Promotion of Traditional National Sports Cultures}

There're plentiful national sports travelling resources in the western region. But many problems have emerged when using these resources to stimulate local economy, like damaging national sports resources, overdevelopment, and even a cultural confusion by transplanting other modern elements to the peculiar national culture. As a result, the national culture is deprived of inherent feature and the loss of traditional national sports culture and cultural fault have been obstacles in the way of continuity of tradtional national sports cultures (Guo et al., 2003). Competitive sports is advancing vibrantly nowadays, in contrast to un recognition and un popularity of national sports events and cultures around the whole society. Consequently, these sports cultures, whose future look bleak, have not been effectively developed to a ethnic sports cultural industry chain.

\subsection{Slow Development of Traditional National Sports Market and Absence of Strong Support}

With the rapid growth of sports market economy in China, the circular market economy has come into being gradually. To start, establish and promote the stimulating mechanism of the circular economy, guaranteeing condition like technology, finance, law, moral and culture as well as support, participation and efforts of government, enterprises and the public (You \& Qi, 2004). Nevertheless, traditional national sports possess rather small share in the whole sports market, and in this market with few consumers, producers, operators and consumers are so immature that their compre-hensive abilities and quality cannot keep up with development of market economy. Moreover, in this defective management mechanism of traditional national sports, an efficient information system of supervision, prewarning, evaluation, development, investment and operation is also absent.

\subsection{Incomprehensive Development of National Sports Resources}

As to the development level of traditional national sports travelling resources, few sports events have been developed owing to the characteristics of those events themselves. The events are so unique, as the local people, for outsiders to participate, so they are only developed as performance, far from realizing their actual value. The developed events, carrying no traditional national characteristics and special connotation, have bad economic results, and are impossible to expand their scale. The best way to develop the traditional national sports travelling resources is to develop them in great scope and depth under correct management and in suitable method, preserving their own charac- 
teristics. And it's also the only way to maximize economic benefit while appreciating the vale of national sports resources at the same time.

\section{Countermeasures for Development of National Sports Resources in West China Based on PSR (Pressure-State-Response) Model}

The framework for development of national sports resources in West China (shown in Figure 3) shows clearly the relationship among factors in the developing process. It's principal to coordinate the three factors, obey the rules and causality for the development of the national sports resources in West China and full use of environmental resources.

Resource developer, travel consumer and local people in ethnic region, as "pressure" in the framework, should "response" efficiently and promptly upon the feedback from sports resources so as to make a readjustment with proper economic measures and developmental activities. Only so can "pressure" change into benign factor to promote economic returns and be beneficial to regional coordinative development, over-all consideration and optimum circular sustainable development.

\subsection{A Win-Win Prosperity in Combination of Sports Resources and the Travelling Resources as a Whole}

The State Council instructed that in the Western Development, the five tasks: the construction of infrastructure, eco-environmental conservation and construction, industry structure adjustment, technology and education, opening up to the outside, which are bound together to the big expansion of sports industry in West China, should be concentrated on. Hence, the inherent requirement to accelerate the development of emerging sports industry with unique feature fits right in with the Western Development strategy in which every specific measure may push forward the development of sports industry in West China (Wang, 2001). We should construct a travelling industrial chain and enhance the reputation. Combining ethnic sports and travelling is a promising way to develop characteristic economy in West China. To this end, we are supposed to make full use of support and help from the government as the Western Development policies, to combine the sports travelling resources with the

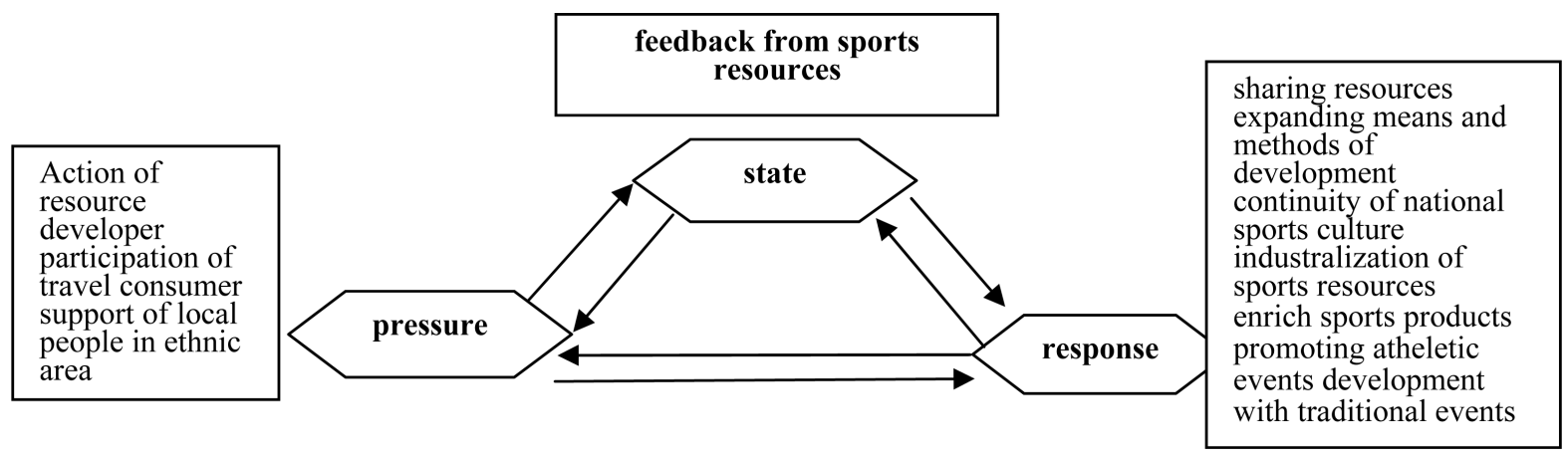

Figure 3. Influencing mechanism of national sports resources based on the PSR model. 
overall resources in West China, to strengthen development of sports travelling products, talent introduction and construction of sports travelling infrastructure, to integrate development of sports resources into the Western Development. Only when we do all this will it be possible to industrialize those resources for economic returns and accelerate economic development in West China in its entirety.

\subsection{Developing New Forms of Sports Resources Development}

Wang Tianjun in Sport Department, Xinjiang University, considers that in West China, for the purpose of transformation from sports resource advantages to economic advantages and industrial advantages, there should be an innovation of forms of sports resources development, adhering to the spirit of market oriented (Wang, 2007). Since there are abundant sports resources in the western region, the development is to be based on an understanding of feature of those traditional national sports events, requiring popularization of those body-building and entertaining events and promotion of those spectator events suitable for performance. To maximize the potential of sports resources in West China needs to correctly classify numerous sports events first, then develop new forms of resources development, and use as many means as possible, such as culture, education and technology, preserving the unique historical characteristics of traditional national sports resources meanwhile. In addition, we ought to fully understand the the sports resources and relevant products in the eastern and western areas, coordinate the sports resources in the eastern, western and central areas for a promotion of the development and industrialization of sports resources all over the country.

\subsection{Strengthening Continuity of National Sports Culture}

In the industrialization of traditional national sports in West China, stress should be put on the fully developing and using cultural characteristics of traditional national sports events, on their good compatibility with other resources in the western area, and on integrating traditional national sports events with national festivals, natural view of western area and other humane tourist resources (Nong, 1999). Developing sports industry in western area by consumption of local people merely and as pure spectator events is far from demands of sports industrialization. Only through combination of national characteristics and cultural spirit and national sports events and various sports, humanity and nature resources can rapid progress be achieved. The unique charming of national sports events with profound cultural deposits, should be disseminated nationwide or even worldwide, so as to attract more and more people in comprehending traditional national sports culture and industry, and being a part in its development. Furthermore, to ensure that ethnic minorities will gain maximum benefit in development of sports industry, we may, in the light of concrete conditions of local people, pay great attention to continuity of national sports culture, enhance the reputation and increase collaborative development in virtuous circle. At the same time, relevant law and registration should be formulated and completed to support the development of national sports resources and sports industry. 


\subsection{Accelerating the Industrialization of Sports Resources}

In development of traditional national sports industry, it is important to increase input on finance, technology, talents, and management in sports industry by all means and expand production scale. We should mobilize all positive factors and make use of advanced manufacturing technique and managing experiences to develop the traditional national sports industry. And we should also enhance our reputation of sports industry in the whole economic industry by active publicity, and make more people know and throw themselves into sports industrialization. Besides, we ought to train talents in producing, operating and marketing fields, increase developmental efficiency of sports industry and make competitive sports products. To build great brand with strong market effect is the best way for traditional national sports industry in China to develop favourably and sustainably and to be one of the most important foundations of development of market economy in China.

\subsection{Diversifying Sports Products}

Sports products with distinctive national features must be developed and designed, conforming to the trend of domestic sports market, to attend to the wants of costumers. And we must enhance cooperation and complementation with the eastern area, then diversify sports products by developing different products for different groups. Meanwhile, we must make full use of high technologies, increase the science and technology content of our products, so as to improve the market competition of sports products, and use technology to promote economic efficiency of sports industry.

\subsection{Promoting Development of Athletics Project by Traditional Strong Events}

Those traditional strong events, like Wrestling, Judo and Equestrianism of Inner Mongolia, Weight Lifting, Gymnastics and Badminton of Guangxi, Middle-distance Race and Walking Race of Yunnan, Toxophily and Equestrianism of Qinghai, are easily to play, because the ethnic groups are remarkably hardy and strong, and those events have good foundation among the masses and there're many first-class players. We need to quicken the construction of current altitude training bases which are expected to endure more national training mission, and improve the level of local athletics projects (Jing \& Li, 2008). There are numerous national sports events in our country and a large number of good athletes. We should improve the development of local athletics projects while developing traditional national sports events, enjoying a mutual promotion and common prosperity of traditional events and athletics projects. We, possessing unique traditional sports events, should stress on key projects by building our strong athletics events, and thereby, enhance the reputation of the western area and seek for a better development of traditional national sports.

\section{Conclusion}

There's obvious causal relationship in the PSR Model. Through economical and social 
activities, the human beings attain necessary resources for their living and development and dump various wastes to the nature through production and consumption. Thus, the human beings have changed natural resources storage and environmental quality as well, in turn, the changes of nature and environment have been influencing the social economical activities and welfare, and then the society responds to these changes by making nature polices, economy polices and sectoral polices, and changing people's conscience and behavior. As a perpetual cycle, the human beings and the environment have had a pressure-state-response relationship. To analyze the development situation of national sports resources in West China, using PSR (Pressure-State-Response) model will effectively help to identify root cause and come up with a countermeasure.

\section{References}

Cheng, Z. L. (1987). A Discussion on Sport Culture. Journal of Shanghai Institute of Physical Education, 3, 15-17.

Guo, X. d., Qiu, Y., \& Lian, G. (2003). The Progress and Prospect of Land Quality Indicators Based on Press-State-Response Framework. Progress in Geography, 5, 479-481.

Jing, F. Y., \& Li, G. F. (2008). A discussion on Developing Actuality and Reasons of Sports Cause in West China. Market Modernization, 6, 33-35.

Nong, Y. (1999). Feasibility and Train of Thought of National Sports in Yunnan. The Journal of Sport History and Culture, 4, 46-49.

OECD (2004). Environmental Indicators: Development Measurement and Use. https://www.coursehero.com/file/10555412/OECDEnvironmentalIndicators-development2Cm easurementanduse/

Qiu, D., \& Song, X. G. (2002). Bridge between Concept Innovation and Policy Implement: Sustainable Development Indicators in Recent Period. Beijing: China Financial \& Economic Publishing House.

Wang, T. J. (2007). A Study on the Leapfrog Development of National Sports Industry in the Western Area. Journal of Beijing Sports University, 11, 68-70.

Wang, Z. W. (2001). Economic Development with Characteristics in the Western Area. Beijing: Ethnic Press of China

You, W., \& Qi, J. G. (2004). Long-Term Trend of Chinese Economy and Recycling Economy. Finance and Trade Economics, 10, 11-12.

Zhang, Z. Q., Cheng, G. D., \& Xu, Z. M. (2002). Review of Indicators and Methodologies for Measuring Sustainable Development and Their Applications. Journal of Glaciology and Geocryology, 4, 344-345. 
Submit or recommend next manuscript to SCIRP and we will provide best service for you:

Accepting pre-submission inquiries through Email, Facebook, LinkedIn, Twitter, etc. A wide selection of journals (inclusive of 9 subjects, more than 200 journals)

Providing 24-hour high-quality service

User-friendly online submission system

Fair and swift peer-review system

Efficient typesetting and proofreading procedure

Display of the result of downloads and visits, as well as the number of cited articles

Maximum dissemination of your research work

Submit your manuscript at: http://papersubmission.scirp.org/

Or contact ape@scirp.org 